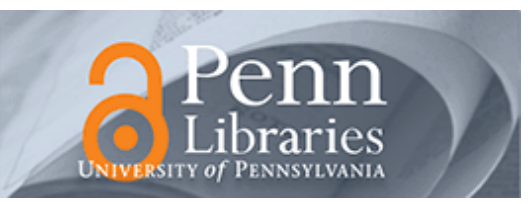

University of Pennsylvania

ScholarlyCommons

7-3-2015

\title{
Self-Care Confidence May be the Key: A Cross-Sectional Study on the Association between Cognition and Self-Care Behaviors in Adults with Heart Failure
}

Ercole Vellone

Roberta Fida

Fabio D'Agostino

Antonella Mattola

Raul Juarez-Vela

See next page for additional authors

Follow this and additional works at: https://repository.upenn.edu/nrs

Part of the Behavioral Medicine Commons, Cardiology Commons, Cardiovascular Diseases

Commons, Circulatory and Respiratory Physiology Commons, Medical Humanities Commons, Neurology

Commons, Nursing Commons, and the Preventive Medicine Commons

\section{Recommended Citation}

Vellone, E., Fida, R., D'Agostino, F., Mattola, A., Juarez-Vela, R., Alvaro, R., \& Riegel, B. (2015). Self-Care Confidence May be the Key: A Cross-Sectional Study on the Association between Cognition and Self-Care Behaviors in Adults with Heart Failure. International Journal of Nursing Studies, 52 (11), 1705-1713. http://dx.doi.org/10.1016/j.ijnurstu.2015.06.013

This paper is posted at ScholarlyCommons. https://repository.upenn.edu/nrs/184

For more information, please contact repository@pobox.upenn.edu. 


\title{
Self-Care Confidence May be the Key: A Cross-Sectional Study on the Association between Cognition and Self-Care Behaviors in Adults with Heart Failure
}

\author{
Abstract \\ Background \\ Self-care, a key element of heart failure care, is challenging for patients with impaired cognition. \\ Mechanisms through which cognitive impairment affects self-care are not currently well defined but \\ evidence from other patient populations suggests that self-efficacy, or task-specific confidence, mediates \\ the relationship between cognitive functioning and patient behaviors such as self-care. \\ Objective
}

The aim of this study was to test the mediating role of self-care confidence in the relationship between cognition and self-care behaviors.

Design

A secondary analysis of data from a cross-sectional study.

Setting

Outpatient heart failure clinics in 28 Italian provinces.

Participants

628 Italian heart failure patients.

Methods

We used the Self-Care of Heart Failure Index v.6.2 to measure self-care maintenance, self-care management, and self-care confidence. Cognition was assessed with the Mini Mental State Examination. Structural equation modeling was used to analyze the data.

Results

Participants were 73 years old on average (SD $=11)$, mostly $(58 \%)$ male and mostly $(77 \%)$ in New York Heart Association functional classes II and III. The mediation model showed excellent fit (comparative fit index $=1.0$; root mean square error of approximation $=0.02$ ): Self-care confidence totally mediated the relationship between cognition and self-care maintenance and management.

Conclusion

Cognition affects self-care behaviors indirectly, through self-care confidence. Interventions aimed at improving self-care confidence may improve self-care, even in heart failure patients with impaired cognition.

\section{Keywords}

cognition, cross-sectional studues, heart failure, medication adherence, mild cognitive impairment, nursing theory, self care, self efficacy

Disciplines

Behavioral Medicine | Cardiology | Cardiovascular Diseases | Circulatory and Respiratory Physiology | 
Medical Humanities | Medicine and Health Sciences | Neurology | Nursing | Preventive Medicine

Author(s)

Ercole Vellone, Roberta Fida, Fabio D'Agostino, Antonella Mattola, Raul Juarez-Vela, Rosaria Alvaro, and Barbara Riegel 


\section{Self-care confidence may be the key: a cross-sectional study on the association between cognition and self-care behaviours in adults with heart failure}

Ercole Vellone, RN, PhD

Research Fellow

Department of Biomedicine and Prevention

University of Rome Tor Vergata, Rome, Italy

Roberta Fida, $\mathrm{PhD}$

Assistant Professor

Department of Psychology

Sapienza University of Rome, Italy

Fabio D’Agostino, RN, PhD

Research Fellow

Department of Biomedicine and Prevention

University of Rome Tor Vergata, Rome, Italy

Antonella Mottola, RN, MSN

PhD Student

Department of Biomedicine and Prevention

University of Rome Tor Vergata, Rome, Italy

Raul Juarez-Vela, RN, PhD

Research Fellow

Faculty of Health Sciences,

University San Jorge, Zaragoza, Spain

Rosaria Alvaro, RN, MSN

Associate Professor

Department of Biomedicine and Prevention

University of Rome Tor Vergata, Rome, Italy

Barbara Riegel, RN, DNSc, FAHA, FAAN

Professor and Edith Clemmer Steinbright Chair of Gerontology

School of Nursing, University of Pennsylvania

Philadelphia, PA USA

Corresponding Author

Dr. Ercole Vellone

Department of Biomedicine and Prevention

University of Rome Tor Vergata

Via Montpellier, 1

Rome 00133, Italy

Phone: + 390672596802

Fax: + 390672596961

Email: ercole.vellone@uniroma2.it

Fundings: This study was funded by the Center of Excellence for Nursing Scholarship, Rome, Italy 


\begin{abstract}
Background: Self-care, a key element of heart failure care, is challenging for patients with impaired cognition. Mechanisms through which cognitive impairment affects self-care are not currently well defined but evidence from other patient populations suggests that self-efficacy, or task-specific confidence, mediates the relationship between cognitive functioning and patient behaviors such as self-care.
\end{abstract}

Objective: The aim of this study was to test the mediating role of self-care confidence in the relationship between cognition and self-care behaviors.

Design: A secondary analysis of data from a cross-sectional study.

Setting: Outpatient heart failure clinics in 28 Italian provinces.

Participants: 628 Italian heart failure patients.

Methods: We used the Self-Care of Heart Failure Index v.6.2 to measure self-care maintenance, self-care management, and self-care confidence. Cognition was assessed with the Mini Mental State Examination.Structural equation modeling was used to analyze the data.

Results:Participants were 73 years old on average ( $\mathrm{SD}=11)$, mostly $(58 \%)$ maleand mostly $(77 \%)$ in New York Heart Association functional classesII and III. The mediation model showed excellent fit $($ comparative fit index $=1.0$; root mean square error of approximation $=0.02)$ : Self-care confidence totally mediated the relationship between cognition and self-care maintenance and management.

Conclusion:Cognition affects self-care behaviors indirectly, through self-care confidence. Interventions aimed at improving self-care confidence may improve self-care, even in heart failure patients with impaired cognition. 
key words:Cognition, Cross-Sectional Studies, Heart Failure,Medication Adherence, Mild Cognitive Impairment,Nursing Theory, Self Care, Self efficacy. 


\section{Introduction}

Heart failure is an extremely prevalent syndrome in developed and developing countries (Go et al., 2014). Outcomes associated with heart failure are poor, with patients experience increasing symptoms as the syndrome progresses (Lam and Smeltzer, 2012). Symptoms are responsible for a decline in functional status, deteriorating health-related quality of life (HRQL), repeated hospitalization, and early demise (Falk et al., 2013, Murthy and Lipman, 2011, Song et al., 2010). A growing body of research demonstrates that self-care by patients can improve these outcomes (Ditewig et al., 2010, Jones et al., 2012, Tung et al., 2013). Self-care involves a process of maintaining physiological stability by monitoring symptoms, adhering to the treatment regimen (self-care maintenance), and promptly identifying and responding to symptoms (self-care management)(Riegel and Dickson, 2008). Clinicians are challenged by the difficulties associated with engaging patients in self-care (Gardetto, 2011).

Self-care requires that patients have knowledge and skills, both of which are influenced by cognition(Dickson et al., 2008). Cognitive impairment is recognized as an issue in $25-50 \%$ of adults with heart failure (Dodson et al., 2013, Gure et al., 2012, Pressler, 2008).Most studies investigating the relationship between cognitive impairment and self-care have demonstrated that heart failure patients with cognitive impairment are poor at self-care.For example, Harkness et al.(2013) found that patients with mild cognitive impairment scored significantly lower in self-care management than those without cognitive impairment.Alosco et al. (2012) found that patients with lower (worse) scores on the Mini Mental Status Examination were more likely to fail in medication management, a dimension of self-care. Smeulders and colleagues (2010)found that heart failure patients with better cognitive status benefitted more from a chronic disease self-management programme compared to patients with poorer cognitive function. Only one investigative team found no relationship between cognition and self-care(Cameron et al., 2009),although in a subsequent study the same investigators(Cameron et al., 2010) found that heart failure patients with mild cognitive impairment exhibited lower self-care management and self-care confidence than patients without 
cognitive impairment. Hajduk et al (2013) found no association between overall cognitive status and self-care in heart failure patients, but when they analyzed specific domains, impaired memory was associated with poor self-care while executive function and processing speed were not. This inconsistency suggests that cognition is not a direct predictor of self-care behaviors in patients with heart failure.

Mechanisms or pathways through which cognitive impairment affects self-care are worth clarifying because they may suggest targets for intervention. One potential mechanism is selfefficacy or task-specific confidence, which has been defined as confidence in the ability to perform the various self-care behaviors (e.g. confidence in one's ability to follow a low salt diet) (Riegel and Dickson, 2008).

The situation specific theory of heart failure self-care (Riegel and Dickson, 2008, Riegel et al., 2015) specifies that self-care maintenance (monitoring of heart failure symptoms and adhering to treatments) influences self-care management (the response of patients to signs and symptoms of a heart failure exacerbation) and that both are influenced by self-care confidence. Therefore, the overall purpose of this study was to test self-care confidenceas mediating the relationship between predictors of self-care and the self-care behaviors of maintenance and management(Riegel and Dickson, 2008).

To date, few researchers have investigated the role of confidence in influencing self-care behaviors. Cene and colleagues (2013)found that perceived emotional and informational support was associated with better self-care maintenance and possibly better self-care management in a sample of heart failure patients. A similar result was found by Sayler et al (2012) who showed that self-care confidence mediated the relationship between social support and self-care maintenance and between social support and self-care management. In a mixed method study Dickson et al.(2008) found that patients with lower self-care confidence and impaired cognition had lapses in self-care behaviors and were classified as "inconsistent" while those with higher self-care confidence and better cognition were better in self-care and were classified as "experts". Building 
on prior studies illustrating thatcognitive impairment and self-care confidence are both predictors of self-care behaviors and building on the situation specific theoryof heart failure self-care that proposes confidence as a mediator of the relationship between self-care behaviours and its predictors, the specific objective of this study was to evaluate whether self-care confidence mediates the relationship between cognition and the self-care behaviors. Specifically we hypothesized that cognition affects self-care maintenance and management only indirectly by its influence on self-care confidence (Figure 1).

\section{Methods}

\section{Design}

A secondary analysis of data from a descriptive, cross-sectional study was performed. The aim of the parent study was to describe self-care and caregiver contributions to self-care in the Italian heart failure population(Cocchieri et al., 2015, Vellone et al., 2014).

\section{Sample and setting}

In the parent study, 1192 patients were enrolled from39 cardiovascular ambulatory clinics located in 28 different provinces in the North, Center and South of Italy. To be enrolled in the study patients had to meet the following inclusion criteria: 1) being diagnosed withheart failure, regardless of type (i.e. either reduced or preserved ejection fraction), confirmed by the treating cardiologist based on echocardiography and clinical evidence (i.e. signs of heart failurelike edema, and common symptoms of heart failurelike dyspnea)as defined in the international guidelines (Dickstein et al., 2008, McMurray et al., 2012);2) being at least 18 years old; and 3) stable (having not experienced an acute coronary syndrome in the three months prior to enrollment). We excluded from enrollment patients with frank dementia.Data collection was performed between January 2011 and November 2012.For the purpose of this study only patients $(n=628)$ who had experienced heart failure symptoms (i.e., those reporting ankle swelling or problem breathing in the last month) 
were considered for the analysis because the self-care management scale cannot be scored when patients have not experienced symptoms. In the comparison between the subsample considered in this analysis and the full sample, this subsample of symptomatic patients was slightly older (73 vs 71.6 years old, $p$ 0.04), less educated ( $p<0.001)$, with a higher New York Heart Association functional class ( $p<0.001)$, with lower ejection fraction $(43.1 \%$ vs $46.4 \%, p<0.001)$, with more comorbid conditions (Charlson Comorbidity Index score 3.1 vs. 2.6, $p<0.001$ ), and had heart failure for a longer duration (55.8 vs 48.1 months of illness, $\mathrm{p}<0.001)$.

\section{Instruments}

Data from the following instruments were used in the analysis.

The Self-Care of Heart Failure Index v.6.2 (SCHFI V.6.2)(Riegel et al., 2009)is a 22 -item instrument, grouped in three scales that measure self-care behaviors and self-efficacy in performing these behaviors. The self-care maintenance scale measures the extent to which patients engage in behaviors aimed at maintaining their physiological stability through monitoring of symptoms (e.g. checking ankle edema) and adhering to treatment (e.g. taking medications). The self-care management scale evaluates the ability of patients to recognize symptoms of a heart failure exacerbation (e.g. weight gain), implement treatment (e.g. limit fluid intake), and evaluate the effectiveness of the interventions tried. The self-care confidence scale measures self-efficacy or task-specific confidence in both self-care maintenance and self-care management. Self-care confidence is theorized to influence self-care, not as a part of self-care per se(Riegel and Dickson, 2008, Riegel et al., 2009).

The SCHFI v.6.2 hasbeen shown to have adequate validity and reliability (Barbaranelli et al., 2014, Riegel et al., 2009)in a variety of populations, including the Italian population (Vellone et al., 2013). Each SCHFI v.6.2 scale (maintenance, management and condifence) uses a standardized score from 0 to 100 where higher scores indicate better self-care.A score $<70$ on each SCHFI v.6.2 scale is considered inadequate self-care (Riegel et al., 2009). 
The Mini Mental State Examination (MMSE) (Folstein et al., 1975)is a 19-item instrument that is widely used to assess global cognitive function. The MMSE assesses orientation to time, orientation to place, attention and calculation, recall of 3 words, language, and visual construction. Possible scores vary between 0 and 30, with higher score indicating better cognition. Scores ranging from 27 to 30 are considered normal in the general population; scores between 21 and 26 reflect mild cognitive impairment; scores between 10 and 19 are considered moderate impairment; a score below 10 is considered severe impairment (Tombaugh and McIntyre, 1992). The MMSE has been used extensively in heart failure patients (Caminiti et al., 2012, Feola et al., 2013). Cronbach's alpha of the MMSE was 0.83 in this study.

The Charlson Comorbidity Index (CCI)(Charlson et al., 1987) is a tool with established validity and reliability designed to measure comorbidity. Quan et al. (2011) updated the CCI into a new versions with 12 items. Each item, which corresponds to a specific disease, can be scored with 1, 2, 3 or 6 ; higher scores indicate higher comorbidity. The total CCI score ranges form 0 to 24 . All patients in this study had a score of at least 2 because this is the score that the updated CCI gives to heart failure.This tool was completed by abstracting data from patient's medical record.

Participants were also queried about their sociodemographic characteristics (e.g. age, gender, education).Clinical information not included in the CCI such as New York Heart Association class, ejection fraction, and illness duration were extracted from the medical record.

\section{Data collection procedure}

This study complied with the Declaration of Helsinki. The study was approved by the Institutional Review Board of each cardiovascular center where patients were enrolled. After the research assistants met the participants, they described the study, obtained informed consent, administered the instruments to patients and collected clinical information from their medical record. All research assistants were trained to administer the MMSE in a consistent fashion. 


\section{Data Analysis}

Sociodemographic and clinical data were analyzed with descriptive statistical procedures (mean, standard deviation, median, interquartile ranges and frequencies). The SCHFI v.6.2 and the MMSE scores were analyzed after computing means and standard deviations. In order to examine the normality of the study variables skeweness and kurtosis were computed. Correlations among the study variables were analyzed with Pearson's r.

Structural equation modeling (Muthén and Muthén, 1998-2012) was conducted to examine the proposed mediation model. Prior to structural equation modeling, in order to avoid a clustering effect due to the cluster structure of our dataset (which included data from 39 cardiovascular ambulatory clinics), intraclass correlations were computed. With clustered data, standard errors and the chi-square fit statistic should be adjusted accordingly, so multilevel structural equation modeling was conducted with MPlus version 7 with the command "TYPE=COMPLEX". This command enables use of an estimation procedurethat includes a Taylor series-like function to provide a normal theory covariance matrix for analysis (Stampleton, 2006). This procedure produces correct parameters estimates, standard error, and test statistics.

Structural equation modeling is a powerful procedure that allowed us to investigate the mediating role of self-care confidence, which simultaneously acts as a dependent variable with respect to MMSE score and as an independent variable with respect to both self-care maintenance

and self-care management (Figure 1). Specifically we examined 1) the influence of MMSE on selfcare maintenance through self-care confidence, and 2) the influence on self-care management through self-care confidence and through self-care confidence and self-care maintenance. In order to verify if a significant direct effect of MMSE on both self-care maintenance and self-care management existed, modification indices were examined.

The estimate of each indirect effect was examined 1) by calculating the products of the regression coefficients of the paths from MMSE to self-care confidence and from self-care confidence to self-care maintencance;2) by calculating the product of the regression coefficients of 
the paths from MMSE to self-care confidence and from self-care confidenceto self-care management; and,finally, 3) by calculating the product of the regression coefficients of the paths from MMSE to self-care confidence, from self-care confidenceto self-care maintenance and from self-care maintenance to self-care management (MacKinnon et al., 2002).Then, the significance of each indirect effect was examined by computing the bias-corrected bootstrap confidence intervals(MacKinnon, 2008, MacKinnon et al., 2004) based on 5,000 bootstrap replications of the initial sample.Age, gender, education, New York Heart Association functional class, Charlson Comorbidity Indexscore and illness duration (months) were included as covariates for all the study variables.

Based on recommendations for a multifaceted approach to the assessment of the model fit (Hoyle, 1995, Tanaka, 1993), several criteria were used to evaluate the fit. These included omnibus fit indices such as the Chi-square $\left(\chi^{2}\right)$ and incremental fit indices such as the Comparative Fit Index (Bentler and Bonnet, 1980). The generally agreed-upon critical value for the Comparative Fit Index is 0.90 or higher (Kline, 2011). In addition, the Root Mean Square Error of Approximation (Steiger, 1990) and the Standardized Root Mean Square Residual (Jöreskog and Sörbom, 1993) were used and evaluated using Hu and Bentler's(1999) criteria that a low value (between 0 and 0.06 for Root Mean Square Error of Approximation and between 0 and 0.08 for Standardized Root Mean Square Residual) indicates a good fitting model. The SPSS version 20 and MPlus version 7 were the two software programs used to analyze the data. Level of significance was set at $\mathrm{p}<0.05$.

\section{Results}

The sample consisted of 628 patients, most (58\%) of whom were male. The mean age of the sample was 73 years $(\mathrm{SD}=11)$ and more than half were educated at only an elementary school level. About one half of the patients were married (55\%) and most were unemployed or retired (86\%). Most (77\%) participants were in New York Heart Association functional class II or III with a mean ejection fraction of $43 \%$. The median time since diagnosis was 4 years (Table 1 ). 
As shown in Table 2 the mean scores of the SCHFI v.6.2 scales were low considering the cut-off score of 70 as adequate. The mean score on the MMSE was 23, which denotes mild cognitive impairment (Tombaugh and McIntyre, 1992). All the variables were normally distributed with both skewness and kurtosis ranging from -1 to 1 . Results of the correlation analysis showed that all the study variables were significantly correlated with each other but the correlations with self-care confidence were the highest (Table 2). Intraclass correlationsranged from .28 to .37 (Table 2) suggesting that the variance at each clinic's level accounted at least for $28 \%$ of the total variance. Consequently, a multilevel structural equation modelingwas conducted to test the mediation model.

The specified model (Figure 2) showed an excellentfit: $\chi^{2}(2)=2.67, p=0.26$; Comparative Fit Index $=1.00 ;$ Root Mean SuareError of Approximation $=0.02(90 \% \mathrm{CI}=0.00-0.09), \mathrm{p}=0.64$; Standardized Root Mean Square Residual $=0.00$. The inspection of the modification indices revealed that there were no other significant paths to be added to improve the model fit. Thus, the results of structural equation modeling demonstrated that MMSE score influenced self-care maintenance and self-care management indirectly through the mediating effects of self-care confidence. Specifically MMSE score predicted self-care confidence and, in turn, self-care confidence predicted both self-care maintenance and self-care management. Finally, self-care maintenance predicted self-care management, as proposed in the theory(Riegel and Dickson, 2008). So as shown in Figure 2, the relationship of MMSE with both self-care maintenance and self-care management was totally mediated by self-care confidence. The tested model also illustrated interesting patterns in terms of the covariates. In particular, higher education, lower New York Heart Association functional class and younger age predicted higher MMSE scores; youngerage and female gender predicted higher self-care confidence scores; longer illness duration predicted higher self-care maintenance scores; finally, higher New York Heart Association functional class predicted lower self-care management. Table 3 reports the nonsignificant paths. Specifically, MMSE scores were not significantly influenced by gender, comorbidity or illness duration; self-care confidence was not influenced by education, New York Heart Association class, comorbidity or illness 
duration; self-care maintenance was not influenced by age, gender, education, New York Heart Association class or comorbidity, although the effect of New York Heart Association class was on the edge $(p=0.05)$; finally, self-care management was not significantly influenced by age, gender, education, comorbidity or illness duration. The above model explained the $16 \%, 28 \%$ and $38 \%$ of variance in self-care confidence, self-care maintenance, and self-care management respectively.

Table 4 shows both the specific and total indirect effects. Specifically, as hypothesized, MMSE significantly influenced self-care maintenance (effect n. 1) and self-care management (effect n. 2) indirectly through self-care confidence. As shown in table 4, the specific effect that MMSE had on self-care management was mainly mediated through confidence (indirect effect estimate $=$ 0.14)rather than through self-care confidence and self-care maintenance (indirect effect estimate $=$ 0.02). But the total indirect effect of MMSE onself-care management, both through self-care confidence (effect n. 3 and through self-care confidence and self-care maintenance (effect n. 4) was $=0.16$.

\section{Discussion}

The aim of this study was to test the mediating role of self-care confidence in the relationship between cognition and self-care maintenance and between cognition and self-care management. Results of our analysis demonstrate that self-care confidence totally mediated the relation between cognition and self-care maintenance, and between cognition and self-care management. That is, cognition did not havea direct influence on self-care behaviours; its influence occurred through its effecton self-care confidence. These results were significant even after controlling for covariates that are known to affect cognition and self-care. Thus, our hypothesis that cognition influences selfcare maintenance and management only indirectly by its influence on self-care confidence was confirmed.In fact, results of the indirect effects indicate that the influence that MMSE exerts on both self-care maintenance and self-care managementwas totally mediated by self-care confidence. 
To our knowledge this is the first study demonstrating the importance of self-care confidence in the relationship between cognition and self-care behaviors. These results might explain why prior studies were inconsistent in finding a significant relationship between cognition and self-care behaviors (Alosco et al., 2012, Cameron et al., 2010, Harkness et al., 2013, Smeulders et al., 2010).It appears that problems with cognitive functioning decrease patients' confidence in their ability to perform self-care, thereby adversely affecting their self-care behaviors. That is, lack of confidence is an important mechanism by which cognition influences self-care behaviors.For example, there may be situations where confidence is low in spite of adequate cognition and this low confidence may impair the patient's ability to perform self-care. But there also may be situations where confidence is high and, in spite of cognitive impairment, patientsare able to perform adequate self-care.

The results of this study build on the prior mixed methods studyby Dickson and colleagues(2008), which illustrated that heart failurepatients who were cognitively impaired lacked self-efficacy and were less vigilant about self-care, while patients with better cognition had higher self-efficacy, more self-care skill, and a positive attitude toward the illness.

From a theoretical perspective this study supports the situation-specific theory of heart failureself-care and the proposition specifying self-care confidence as a mediator between predictors of self-care behaviors and self-care behaviors themselves (Riegel and Dickson, 2008, Riegel et al., 2015). Self-care confidence has been analyzed as mediator in only two other studies, as far as we are aware (Cene et al., 2013, Salyer et al., 2012). In both studies, self-care confidence mediated the relationship between social support and self-care behaviors. Together, these results demonstrate the powerful influence of confidence in enhancing self-care behaviors and illustrates the importance of interventions that augment patients' confidence.

Self-care confidence, as it was theorized (Riegel and Dickson, 2008, Riegel et al., 2015) and measured (Riegel et al., 2009), reflects self-efficacy in specific self-care behaviors (e.g., selfefficacy in managing heart failuresymptoms). Self-efficacy is not a personality trait but a belief that 
one will be successful in performing specific tasks. Several non-experimental longitudinal studies have shown that self-efficacy is stable and does not change over time in heart failurepopulations(Chen et al., 2013, Goodman et al., 2013, Romppel et al., 2013). However, with specific interventions, self-efficacy can be improved. In fact, three trials (Flynn et al., 2005, Pozehl et al., 2010, Smeulders et al., 2010) in which the interventions were based on social cognitive theory have demonstrated that self-efficacy can be improved in heart failurepatients. In these studies the four determinants of self-efficacy defined by Bandura (1995), performance accomplishments, vicarious experience, verbal persuasion, and emotional arousal, were adapted to heart failurecare and improved self-efficacy. For example, in the study by Pozehl et al (2010), aimed at improving physical activity in heart failurepatients, performance accomplishment consisted of rewarding and celebrating accomplishments; vicarious experience consisted of role modeling; verbal persuasion was performed by a cardiologist who presented the benefits of physical activity in heart failure; lastly, emotional arousal consisted of educating patients on symptom assessment. Hence, even though social cognitive theory is very broad, its principles seem suitable for HF patients as an approach to improving self-efficacy and consequently self-care behaviors.

One may question if the physical and cognitive burden of heart failure, namely poor functional class and cognitive impairment, can affect self-care confidence. New York Heart Association function class, a covariate in our model, was found to influence cognition and self-care management but not self-care confidence. Because self-care confidence is considered a predictor of self-care behaviors, investigators have paid little attention to finding predictors of self-care confidence. Those investigators who have considered the relationship between New York Heart Association functional class and self-care confidence have found inconsistent results. For example, Riegel and colleague (2009) showed that higher New York Heart Associationclass predicted lower self-efficacy, but Cameron et al (2010)found that New York Heart Associationclass was not a predictor of self-care confidence. Further research is needed to understand this relationship well. 
Mild cognitive impairment, which is common inheart failurepatients, clearly affects selfcare confidence, as shown in our model. But one may question the extent to which cognitive impairment impacts self-care confidence and in turn self-care behaviors. In our analysis MMSE score, along with age and gender, explained only the $16 \%$ of the variance of self-care confidence. A clinical trial conducted on heart failure patients with mild cognitive impairment (Davis et al., 2012) showed that an intervention based on cognitive training was able to improve patients' knowledge ofheart failurebut neither self-care confidence nor self-care behaviors improved. The authors commented that because self-care confidence is a mediator of self-care behaviors, "self-care behaviours may not improve as a function of increased knowledge, but more as a function of confidence" (p. 1047). In fact, those trials where the approach was based on improving self-care confidence and not only knowledge (Flynn et al., 2005, Pozehl et al., 2010, Smeulders et al., 2010) were successful in improving self-care behaviors. Also, in other populations where patients were all affected by mild cognitive impairment (Cox et al., 2013), interventions aimed at improving selfefficacy improved patients' outcomes such as physical activity. Based on the results of our study and others in the literature, it appears that cognitive impairment may affect self-care behaviors in heart failure patients but not as significantly as cognition affects self-care confidence.

Building on social cognitive theory (Bandura, 1995), we might predict that most variables influencing self-care could be mediated by self-efficacy. So, even when a specific factor decreases self-care, if heart failurepatients believe that the behavior is important for their health (outcome expectation) and feel confident in their ability to perform the behavior (efficacy expectation) - in this case, self-care- they can be successful.

The results of this study have important implications for practice since they suggest that interventions that augment confidence can have an important effect on self-care, even in patients with cognitive impairment. Since few specific treatments for cognitive impairment in heart failure patients have been identified (Pressler et al., 2011), these results suggest that efforts to improve selfcare confidence may help to improve self-care behaviors in heart failure patients with impaired 
cognition. Because three trials have already shown that the four determinants of self-efficacy work well for heart failure patients, examples of practical approaches might be the following. 1) Focus on performance accomplishments: patients can be educated by doing, letting them acquire specific skills such as how to record their daily weights. Also, rewardpatients for even minimal success in adhering to self-care behaviors; 2) Vicarious experience are important: Consider introducing patients to other patients who have mastered self-care, especially at the beginning of the illness,; 3) Verbal persuasion is effective: Tell patients that they have the capability to care for themselves and emphasize that they can trust themselves as they become experts in self-care; 4) For emotional arousal, provide emotional support to patients and encourage families to be supportive.

This study has a number of limitations. The most important is that we measured global cognition using a screening test (Riley and Arslanian-Engoren, 2013)and did not measure specific cognitive functions such as memory, working memory, psychomotor speed, reasoning, executive function as others have done (Alosco et al., 2012, Riegel et al., 2012). However this was a first study exploring how self-efficacy influences the relationship between cognition and self-care behaviors. Thus, these results suggest a direction for future research. Another limitation was the cross-sectional design using a convenience sample that was symptomatic in the past month. Thus, the results can be generalized only to patients who were recently symptomatic. Also, this Italian sample had a significantly lower level of formal education than found in most published studies of heart failure patients so results of this study should be generalized with caution. We were not able to consider anxiety and depression because these variables were not collected. Anxiety and depression mayaffect self-efficacy and self-care behaviors (Clark et al., 2014, Maeda et al., 2013), so these variables should be measured in future studies.

Authors of a recent literature review (Riley and Arslanian-Engoren, 2013) commented that research on the relationship between cognition and heart failure self-care is still insufficient. In particular there is a need to explore the relationship between memory, executive function, decision making and self-care decision making. Future studies should analyze the effect of self-care 
confidence in influencing these cognitive functions. Research identifying other predictors of selfefficacy in heart failure patients is needed as well.

Conflict of interest: none declared 


\section{References}

Alosco, M.L., Spitznagel, M.B., Cohen, R., Sweet, L.H., Colbert, L.H., Josephson, R., Waechter, D., Hughes, J., Rosneck, J., Gunstad, J., 2012. Cognitive impairment is independently associated with reduced instrumental activities of daily living in persons with heart failure. $\mathrm{J}$ Cardiovasc Nurs 27 (1), 44-50.

Bandura, A., 1995. Self-efficacy in changing societies. Cambridge University Press, New York.

Barbaranelli, C., Lee, C.S., Vellone, E., Riegel, B., 2014. Dimensionality and Reliability of the Self-Care of Heart Failure Index Scales: Further Evidence From Confirmatory Factor Analysis. Research in Nursing \& Health, n/a-n/a.

Bentler, P.M., Bonnet, D.G., 1980. Significante tests and goodnessof fit in the analysis of covariance structures. Psychological Bulletin 88 (3), 588-606.

Cameron, J., Worrall-Carter, L., Page, K., Riegel, B., Lo, S.K., Stewart, S., 2010. Does cognitive impairment predict poor self-care in patients with heart failure? Eur J Heart Fail 12 (5), 508515.

Cameron, J., Worrall-Carter, L., Riegel, B., Lo, S.K., Stewart, S., 2009. Testing a model of patient characteristics, psychologic status, and cognitive function as predictors of self-care in persons with chronic heart failure. Heart Lung 38 (5), 410-418.

Caminiti, G., Ranghi, F., De Benedetti, S., Battaglia, D., Arisi, A., Franchini, A., Facchini, F., Cioffi, V., Volterrani, M., 2012. Cognitive impairment affects physical recovery of patients with heart failure undergoing intensive cardiac rehabilitation. Rehabilitation Research and Practice 2012, 218928.

Cene, C.W., Haymore, L.B., Dolan-Soto, D., Lin, F.C., Pignone, M., Dewalt, D.A., Wu, J.R., Jones, C.D., Corbie-Smith, G., 2013. Self-care confidence mediates the relationship between perceived social support and self-care maintenance in adults with heart failure. Journal of Cardiac Failure 19 (3), 202-210. 
Charlson, M.E., Pompei, P., Ales, K.L., MacKenzie, C.R., 1987. A new method of classifying prognostic comorbidity in longitudinal studies: development and validation. J Chronic Dis $40(5), 373-383$.

Chen, A.M., Yehle, K.S., Albert, N.M., Ferraro, K.F., Mason, H.L., Murawski, M.M., Plake, K.S., 2013. Health Literacy Influences Heart Failure Knowledge Attainment but Not SelfEfficacy for Self-Care or Adherence to Self-Care over Time. Nurs Res Pract 2013, 353290. Clark, A.P., McDougall, G., Riegel, B., Joiner-Rogers, G., Innerarity, S., Meraviglia, M., Delville, C., Davila, A., 2014. Health Status and Self-care Outcomes After an Education-Support Intervention for People With Chronic Heart Failure. Journal of Cardiovascular Nursing.

Cocchieri, A., Riegel, B., D'Agostino, F., Rocco, G., Fida, R., Alvaro, R., Vellone, E., 2015. Describing self-care in Italian adults with heart failure and identifying determinants of poor self-care. Eur J Cardiovasc Nurs 14 (2), 126-136.

Cox, K.L., Flicker, L., Almeida, O.P., Xiao, J., Greenop, K.R., Hendriks, J., Phillips, M., Lautenschlager, N.T., 2013. The FABS trial: a randomised control trial of the effects of a 6month physical activity intervention on adherence and long-term physical activity and selfefficacy in older adults with memory complaints. Preventive Medicine 57 (6), 824-830.

Davis, K.K., Mintzer, M., Dennison Himmelfarb, C.R., Hayat, M.J., Rotman, S., Allen, J., 2012. Targeted intervention improves knowledge but not self-care or readmissions in heart failure patients with mild cognitive impairment. European Journal of Heart Failure 14 (9), 1041 1049.

Dickson, V.V., Deatrick, J.A., Riegel, B., 2008. A typology of heart failure self-care management in non-elders. European Journal of Cardiovascular Nursing 7 (3), 171-181.

Dickstein, K., Cohen-Solal, A., Filippatos, G., McMurray, J.J., Ponikowski, P., Poole-Wilson, P.A., Stromberg, A., van Veldhuisen, D.J., Atar, D., Hoes, A.W., Keren, A., Mebazaa, A., Nieminen, M., Priori, S.G., Swedberg, K., Vahanian, A., Camm, J., De Caterina, R., Dean, V., Funck-Brentano, C., Hellemans, I., Kristensen, S.D., McGregor, K., Sechtem, U., Silber, 
S., Tendera, M., Widimsky, P., Zamorano, J.L., 2008. ESC Guidelines for the diagnosis and treatment of acute and chronic heart failure 2008: the Task Force for the Diagnosis and Treatment of Acute and Chronic Heart Failure 2008 of the European Society of Cardiology. Developed in collaboration with the Heart Failure Association of the ESC (HFA) and endorsed by the European Society of Intensive Care Medicine (ESICM). European Heart Journal 29 (19), 2388-2442.

Ditewig, J.B., Blok, H., Havers, J., van Veenendaal, H., 2010. Effectiveness of self-management interventions on mortality, hospital readmissions, chronic heart failure hospitalization rate and quality of life in patients with chronic heart failure: a systematic review. Patient Educ Couns 78 (3), 297-315.

Dodson, J.A., Truong, T.T., Towle, V.R., Kerins, G., Chaudhry, S.I., 2013. Cognitive impairment in older adults with heart failure: prevalence, documentation, and impact on outcomes. Am J Med $126(2), 120-126$.

Falk, H., Ekman, I., Anderson, R., Fu, M., Granger, B., 2013. Older Patients' Experiences of Heart Failure-An Integrative Literature Review. J Nurs Scholarsh.

Feola, M., Garnero, S., Vallauri, P., Salvatico, L., Vado, A., Leto, L., Testa, M., 2013. Relationship between Cognitive Function, Depression/Anxiety and Functional Parameters in Patients Admitted for Congestive Heart Failure. Open Cardiovascular Medicine Journal 7, 54-60.

Flynn, K.J., Powell, L.H., Mendes de Leon, C.F., Munoz, R., Eaton, C.B., Downs, D.L., Silver, M.A., Calvin, J.E., 2005. Increasing self-management skills in heart failure patients: a pilot study. Congest Heart Fail 11 (6), 297-302.

Folstein, M.F., Folstein, S.E., McHugh, P.R., 1975. Mini Mental State. Apractical method for grading the cognitive state of the patients for the clinicians. Journal of Psychiatric Research $12,189-198$.

Gardetto, N.J., 2011. Self-management in heart failure: where have we been and where should we go? Journal of Multidisciplinary Healthcare 4, 39-51. 
Go, A.S., Mozaffarian, D., Roger, V.L., Benjamin, E.J., Berry, J.D., Blaha, M.J., Dai, S., Ford, E.S., Fox, C.S., Franco, S., Fullerton, H.J., Gillespie, C., Hailpern, S.M., Heit, J.A., Howard, V.J., Huffman, M.D., Judd, S.E., Kissela, B.M., Kittner, S.J., Lackland, D.T., Lichtman, J.H., Lisabeth, L.D., Mackey, R.H., Magid, D.J., Marcus, G.M., Marelli, A., Matchar, D.B., McGuire, D.K., Mohler, E.R., 3rd, Moy, C.S., Mussolino, M.E., Neumar, R.W., Nichol, G., Pandey, D.K., Paynter, N.P., Reeves, M.J., Sorlie, P.D., Stein, J., Towfighi, A., Turan, T.N., Virani, S.S., Wong, N.D., Woo, D., Turner, M.B., American Heart Association Statistics, C., Stroke Statistics, S., 2014. Heart disease and stroke statistics--2014 update: a report from the American Heart Association. Circulation 129 (3), e28-e292.

Goodman, H., Firouzi, A., Banya, W., Lau-Walker, M., Cowie, M.R., 2013. Illness perception, selfcare behaviour and quality of life of heart failure patients: a longitudinal questionnaire survey. International Journal of Nursing Studies 50 (7), 945-953.

Gure, T.R., Blaum, C.S., Giordani, B., Koelling, T.M., Galecki, A., Pressler, S.J., Hummel, S.L., Langa, K.M., 2012. Prevalence of cognitive impairment in older adults with heart failure. J Am Geriatr Soc 60 (9), 1724-1729.

Hajduk, A.M., Kiefe, C.I., Person, S.D., Gore, J.G., Saczynski, J.S., 2013. Cognitive Change in Heart Failure: A Systematic Review. Circulation Cardiovascular quality and outcomes 6 (4), $451-460$.

Harkness, K., Heckman, G.A., Akhtar-Danesh, N., Demers, C., Gunn, E., McKelvie, R.S., 2013. Cognitive function and self-care management in older patients with heart failure. Eur J Cardiovasc Nurs.

Hoyle, R.H., 1995. Structural equation modeling: concepts, issues, and application. Sage, Thousands Oaks, CA

Hu, L., Bentler, P.M., 1999. Cutoff criteria for fit indexes in covariance structure analysis: Conventional criteria versus new alternatives. Struct Equ Modeling 6 (1), 1-55. 
Jones, C.D., Holmes, G.M., Dewalt, D.A., Erman, B., Broucksou, K., Hawk, V., Cene, C.W., Wu, J.R., Pignone, M., 2012. Is adherence to weight monitoring or weight-based diuretic selfadjustment associated with fewer heart failure-related emergency department visits or hospitalizations? J Card Fail 18 (7), 576-584.

Jöreskog, K.G., Sörbom, D., 1993. LISREL8 User's Reference Guide. Scientific Software International, Lincolnwood, IL.

Kline, R., 2011. Principles and practice of structural equation modeling. The Guilford Press, New York.

Lam, C., Smeltzer, S.C., 2012. Patterns of Symptom Recognition, Interpretation, and Response in Heart Failure Patients: An Integrative Review. Journal of Cardiovascular Nursing 28 (4), 348-359.

MacKinnon, D., Lockwood, C., Hoffman, J., West, S., Sheets, V., 2002. A comparison of methods to test mediation and other intervening variable effects. Psychological Methods 7, 83-104.

MacKinnon, D.P., 2008. Introduction to statistical mediation analysis. Erlbaum, Mahwah, NJ.

MacKinnon, D.P., Lockwood, C.M., Williams, J., 2004. Confidence limits for the indirect effect: Distribution of the product and resampling methods. Multivariate Behavioral Research 39 $(99-128)$.

Maeda, U., Shen, B.J., Schwarz, E.R., Farrell, K.A., Mallon, S., 2013. Self-efficacy mediates the associations of social support and depression with treatment adherence in heart failure patients. Int J Behav Med 20 (1), 88-96.

McMurray, J.J., Adamopoulos, S., Anker, S.D., Auricchio, A., Bohm, M., Dickstein, K., Falk, V., Filippatos, G., Fonseca, C., Gomez-Sanchez, M.A., Jaarsma, T., Kober, L., Lip, G.Y., Maggioni, A.P., Parkhomenko, A., Pieske, B.M., Popescu, B.A., Ronnevik, P.K., Rutten, F.H., Schwitter, J., Seferovic, P., Stepinska, J., Trindade, P.T., Voors, A.A., Zannad, F., Zeiher, A., Task Force for the, D., Treatment of, A., Chronic Heart Failure of the European Society of, C., Bax, J.J., Baumgartner, H., Ceconi, C., Dean, V., Deaton, C., Fagard, R., 
Funck-Brentano, C., Hasdai, D., Hoes, A., Kirchhof, P., Knuuti, J., Kolh, P., McDonagh, T., Moulin, C., Popescu, B.A., Reiner, Z., Sechtem, U., Sirnes, P.A., Tendera, M., Torbicki, A., Vahanian, A., Windecker, S., McDonagh, T., Sechtem, U., Bonet, L.A., Avraamides, P., Ben Lamin, H.A., Brignole, M., Coca, A., Cowburn, P., Dargie, H., Elliott, P., Flachskampf, F.A., Guida, G.F., Hardman, S., Iung, B., Merkely, B., Mueller, C., Nanas, J.N., Nielsen, O.W., Orn, S., Parissis, J.T., Ponikowski, P., Guidelines, E.S.C.C.f.P., 2012. ESC guidelines for the diagnosis and treatment of acute and chronic heart failure 2012: The Task Force for the Diagnosis and Treatment of Acute and Chronic Heart Failure 2012 of the European Society of Cardiology. Developed in collaboration with the Heart Failure Association (HFA) of the ESC. Eur J Heart Fail 14 (8), 803-869.

Murthy, S., Lipman, H.I., 2011. Management of end-stage heart failure. Prim Care 38 (2), 265-276. Muthén, L.K., Muthén, B.O., 1998-2012. Mplus User's Guide. Muthén \& Muthén, Los Angeles, CA.

Pozehl, B., Duncan, K., Hertzog, M., Norman, J.F., 2010. Heart Failure Exercise And Training Camp: effects of a multicomponent exercise training intervention in patients with heart failure. Heart Lung 39 (6 Suppl), S1-13.

Pressler, S.J., 2008. Cognitive functioning and chronic heart failure: a review of the literature (2002-July 2007). J Cardiovasc Nurs 23 (3), 239-249.

Pressler, S.J., Therrien, B., Riley, P.L., Chou, C.C., Ronis, D.L., Koelling, T.M., Smith, D.G., Sullivan, B.J., Frankini, A.M., Giordani, B., 2011. Nurse-Enhanced Memory Intervention in Heart Failure: the MEMOIR study. J Card Fail 17 (10), 832-843.

Quan, H., Li, B., Couris, C.M., Fushimi, K., Graham, P., Hider, P., Januel, J.M., Sundararajan, V., 2011. Updating and validating the Charlson comorbidity index and score for risk adjustment in hospital discharge abstracts using data from 6 countries. Am J Epidemiol 173 (6), 676682. 
Riegel, B., Dickson, V.V., 2008. A situation-specific theory of heart failure self-care. Journal of Cardiovascular Nursing 23 (3), 190-196.

Riegel, B., Dickson, V.V., Faulkner, K.M., 2015. The Situation-Specific Theory of Heart Failure Self-Care: Revised and Updated. J Cardiovasc Nurs.

Riegel, B., Driscoll, A., Suwanno, J., Moser, D.K., Lennie, T.A., Chung, M.L., Wu, J.R., Dickson, V.V., Carlson, B., Cameron, J., 2009. Heart failure self-care in developed and developing countries. J Card Fail 15 (6), 508-516.

Riegel, B., Lee, C.S., Dickson, V.V., Carlson, B., 2009. An update on the self-care of heart failure index. Journal of Cardiovascular Nursing 24 (6), 485-497.

Riegel, B., Lee, C.S., Glaser, D., Moelter, S.T., 2012. Patterns of Change in Cognitive Function over Six Months in Adults with Chronic Heart Failure. Cardiology Research and Practice 2012,631075 .

Riley, P., Arslanian-Engoren, C., 2013. Cognitive dysfunction and self-care decision making in chronic heart failure: A review of the literature. European Journal of Cardiovascular Nursing.

Romppel, M., Herrmann-Lingen, C., Wachter, R., Edelmann, F., Dungen, H.D., Pieske, B., Grande, G., 2013. A short form of the General Self-Efficacy Scale (GSE-6): Development, psychometric properties and validity in an intercultural non-clinical sample and a sample of patients at risk for heart failure. Psychosoc Med 10, Doc01.

Salyer, J., Schubert, C.M., Chiaranai, C., 2012. Supportive relationships, self-care confidence, and heart failure self-care. Journal of Cardiovascular Nursing 27 (5), 384-393.

Sayler, J., Schubert, C.M., Chiaranai, C., 2012. Supportive relationships, self-care confidence, and heart failure self-care. Journal of Cardiovascular Nursing 27, 384-393.

Smeulders, E.S., van Haastregt, J.C., Ambergen, T., Stoffers, H.E., Janssen-Boyne, J.J., UszkoLencer, N.H., Gorgels, A.P., Lodewijks-van der Bolt, C.L., van Eijk, J.T., Kempen, G.I., 
2010. Heart failure patients with a lower educational level and better cognitive status benefit most from a self-management group programme. Patient Educ Couns 81 (2), 214-221.

Smeulders, E.S., van Haastregt, J.C., Ambergen, T., Uszko-Lencer, N.H., Janssen-Boyne, J.J., Gorgels, A.P., Stoffers, H.E., Lodewijks-van der Bolt, C.L., van Eijk, J.T., Kempen, G.I., 2010. Nurse-led self-management group programme for patients with congestive heart failure: randomized controlled trial. J Adv Nurs 66 (7), 1487-1499.

Song, E.K., Moser, D.K., Rayens, M.K., Lennie, T.A., 2010. Symptom clusters predict event-free survival in patients with heart failure. J Cardiovasc Nurs 25 (4), 284-291.

Stampleton, L., 2006. An assessment of practical solutions for structural equation modeling with complex sample data. Structural Equation Modeling 13, 28-58.

Steiger, J.H., 1990. Structural model evaluation and modification: An interval estimation approach. Multivariate Behavioral Research 25 (2), 173-180.

Tanaka, J.S., 1993. Multifaceted Conceptions of Fit. In: Kennet, A.B., Long, J.S. (Eds.), Structural Equation Models. Sage, Newbury Park, CA, pp. 10-39.

Tombaugh, T., McIntyre, N., 1992. The mini-mental state examination: a comprehensive review. J Am Geriatr Soc 40 (9), 922-935.

Tung, H.H., Lin, C.Y., Chen, K.Y., Chang, C.J., Lin, Y.P., Chou, C.H., 2013. Self-Management Intervention to Improve Self-Care and Quality of Life in Heart Failure Patients. Congest Heart Fail 19 (4), E9-E16.

Vellone, E., D'Agostino, F., Buck, H.G., Fida, R., Spatola, C.F., Petruzzo, A., Alvaro, R., Riegel, B., 2014. The key role of caregiver confidence in the caregiver's contribution to self-care in adults with heart failure. Eur J Cardiovasc Nurs.

Vellone, E., Riegel, B., Cocchieri, A., Barbaranelli, C., D'Agostino, F., Antonetti, G., Glaser, D., Alvaro, R., 2013. Psychometric properties of the self-care of heart failure index version 6.2. Res Nurs Health 36 (5), 500-511. 


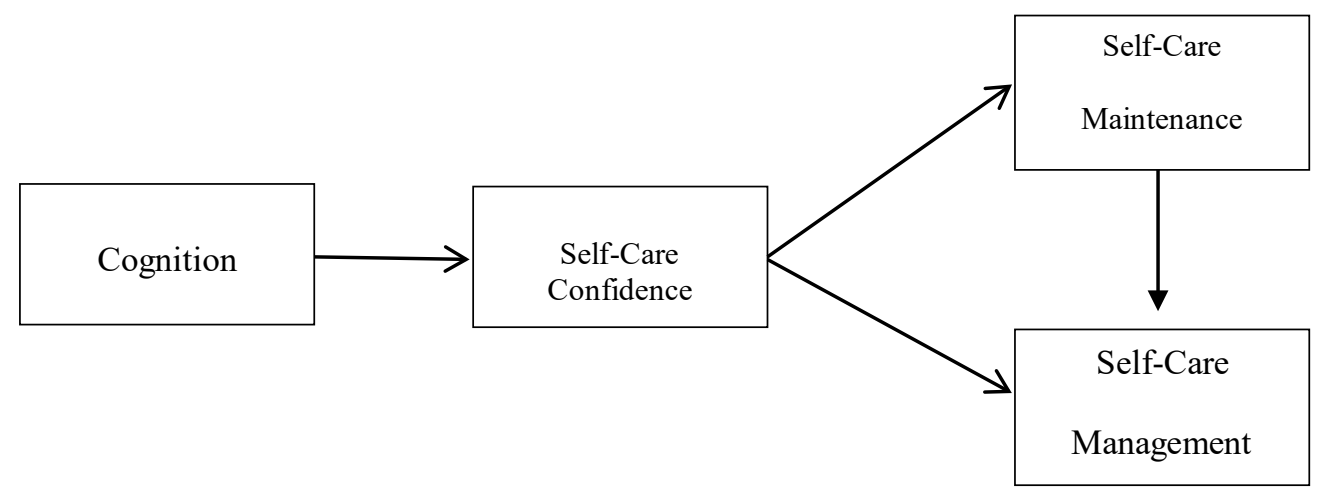

Figure 1. The hypothesized model used to guide the analysis 


\section{Table 1}

Sociodemographic and Clinical Characteristics of the Sample $(\mathrm{N}=628)$

\begin{tabular}{|c|c|c|}
\hline Variables & $n$ & $(\%)$ \\
\hline \multicolumn{3}{|l|}{ Gender } \\
\hline Male & 362 & $(57.60)$ \\
\hline Female & 266 & $(42.40)$ \\
\hline Age (Mean - SD) & 72.98 & (11.34) \\
\hline \multicolumn{3}{|l|}{ Education } \\
\hline Elementary & 326 & $(52.90)$ \\
\hline Middle School & 151 & $(24.20)$ \\
\hline Professional School & 43 & $(6.90)$ \\
\hline High School & 74 & $(11.70)$ \\
\hline University Degree & 33 & $(5.30)$ \\
\hline \multicolumn{3}{|l|}{ Marital Status } \\
\hline Married & 345 & $(54.90)$ \\
\hline Single & 49 & $(7.80)$ \\
\hline Widowed & 197 & $(31.40)$ \\
\hline Divorced & 37 & $(5.90)$ \\
\hline \multicolumn{3}{|l|}{ Job } \\
\hline Employed & 86 & $(13.70)$ \\
\hline Unemployed or retired & 542 & $(86.30)$ \\
\hline \multicolumn{3}{|l|}{ NYHA Class } \\
\hline I & 56 & $(8.90)$ \\
\hline II & 231 & $(36.80)$ \\
\hline III & 262 & $(41.80)$ \\
\hline IV & 78 & $(12.40)$ \\
\hline Ejection Fraction (\%) (Mean - SD) & 43.13 & $(11.55)$ \\
\hline Years Since Diagnosis & 4.0 & $(2-6)$ \\
\hline (Median - Interquatile ranges) & & \\
\hline
\end{tabular}


Table 2

Descriptive statistics of the used scales

\begin{tabular}{lcccccccc}
\hline \multicolumn{1}{c}{ Measure } & M & SD & Skeweness & Kurtosis & ICC & 1 & 2 & 3 \\
\hline Self-care Maintenance & 54.98 & 15.70 & 0.17 & -0.07 & 0.28 & - & & \\
Self-care Management & 53.18 & 20.01 & 0.00 & -0.39 & 0.36 & $0.41^{* *}$ & - & \\
Self-care Confidence & 53.96 & 20.55 & 0.18 & -0.06 & 0.29 & $0.51^{* *}$ & $0.58^{* *}$ & - \\
MMSE & 23.25 & 6.26 & -0.87 & -0.09 & 0.37 & $0.22^{* *}$ & $0.28^{* *}$ & $0.35^{* *}$ \\
\hline
\end{tabular}

Note $. \mathrm{M}=$ Mean; $\mathrm{SD}=$ Standard deviation; $\mathrm{MMSE}=$ Mini Mental State Examination; $\mathrm{ICC}=$ Intraclass Correlation Ciefficient; 1 = Self-Care Maintenance; 2 = Self-Care Management; 3 = Self-Care Confidence; $* *=p<0.01$ 


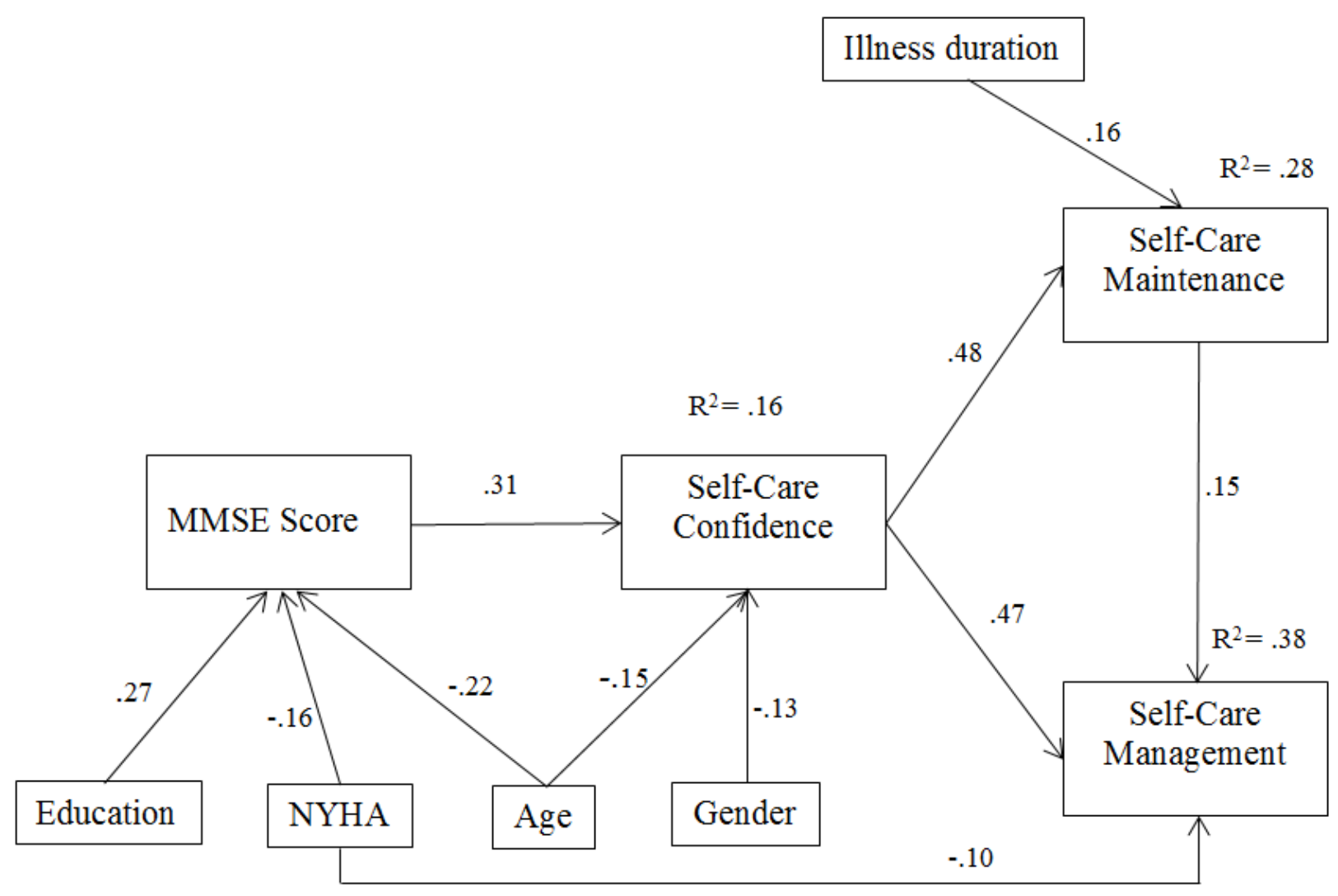

Figure 2. The tested mediation model

Note. Figure reports only significant paths. Gender: $0=$ female; $1=$ male; MMSE $=$ Mini Mental State Examination; NYHA = New York Heart Association Functional Class. Illness duration was measured as months of illness and converted into years. 
Table 3

Non-significant paths among variables included in the structural equation model

\begin{tabular}{|c|c|c|}
\hline Paths & $\begin{array}{c}\text { Standardized } \\
\text { estimate }\end{array}$ & P-values \\
\hline Gender $\rightarrow$ MMSE & 0.00 & 0.90 \\
\hline $\mathrm{CCI} \rightarrow \mathrm{MMSE}$ & -0.07 & 0.06 \\
\hline Illness duration (months) $\rightarrow$ MMSE & -0.03 & 0.38 \\
\hline Education $\rightarrow$ Self-Care Confidence & 0.04 & 0.29 \\
\hline NYHA $\rightarrow$ Self-Care Confidence & 0.03 & 0.39 \\
\hline CCI $\rightarrow$ Self-Care Confidence & 0.05 & 0.21 \\
\hline Illness duration (months) $\rightarrow$ Self-Care Confidence & 0.03 & 0.40 \\
\hline Age $\rightarrow$ Self-Care Maintenance & -0.02 & 0.54 \\
\hline Gender $\rightarrow$ Self-Care Maintenance & 0.01 & 0.77 \\
\hline Education $\rightarrow$ Self-Care Maintenance & 0.07 & 0.06 \\
\hline NYHA $\rightarrow$ Self-Care Maintenance & -0.07 & 0.05 \\
\hline CCI $\rightarrow$ Self-Care Maintenance & 0.01 & 0.64 \\
\hline Age $\rightarrow$ Self-Care Management & -0.01 & 0.70 \\
\hline Gender $\rightarrow$ Self-Care Management & -0.6 & 0.06 \\
\hline Education $\rightarrow$ Self-Care Management & 0.05 & 0.20 \\
\hline $\mathrm{CCI} \rightarrow$ Self-Care Management & -0.04 & 0.20 \\
\hline Illness duration (months) $\rightarrow$ Self-Care Management & -0.05 & 0.14 \\
\hline
\end{tabular}

Note. MMSE = Mini Mental State Examination; CCI = Charlson Comorbidity Index; NYHA = New York Hear Association Class. 


\section{Table 4}

Specific and total indirect effects

IE Estimate

P-values

Specific Indirect effects of MMSE on Self-care Maintenance and Management

1. MMSE $\rightarrow$ Self-care Confidence $\rightarrow$ Self-care Maintenance

$0.15 \quad 0.000$

2. MMSE $\rightarrow$ Self-care Confidence $\rightarrow$ Self-care Management

$0.14 \quad 0.000$

3. MMSE $\rightarrow$ Self-care Confidence $\rightarrow$ Self-care Maintenance $\rightarrow$ Self-care Management

0.02

0.004

Total indirect effect of MMSE on Self-care Management

4. MMSE $\rightarrow$ Self-care Confidence $\rightarrow$ Self-care Maintenance $\rightarrow$ Self-care Management

0.16

0.000

Note. MMSE = Mini Mental State Examination; IE = Indirect effect. Each specific indirect effect was estimated by calculating the product of the regression coefficients. The significance of each indirect effect was examined by computing the bias-corrected bootstrap confidence intervals (MacKinnon, 2008; MacKinnon et al 2004), based on 5,000 bootstrap replications of the initial sample. The total indirect effect of MMSE on Self-care Management (effect n. 4) was estimated by summing the specific indirect effects (effect n. 2 plus effect number 3). 